\title{
The Impact of COVID-19 on Surgery and Procedures: A Commentary
}

Frank Annie $^{1}$, Jaineet Singh Chhabra ${ }^{1}$, and Aravinda Nanjundappa ${ }^{1}$

${ }^{1}$ Affiliation not available

November 3, 2020

The Impact of COVID-19 on Surgery and Procedures: A Commentary

Frank H Annie, $\mathrm{PhD}^{1}$; Jaineet Singh Chhabra ${ }^{3}$; Aravinda Nanjundappa, $\mathrm{MD}^{2}$;

${ }^{1}$ CAMC Health Education and Research Institute

3200 MacCorkle Ave. SE, Charleston, WV 25304.

${ }^{2}$ CAMC Vascular Center of Excellence, Charleston Area Medical Center.

3200 MacCorkle Ave SE, Charleston, WV 25304

${ }^{3}$ Marshall University, School of Medicine.

1600 Medical Center Dr, Huntington, WV 25701

Study Locations:

Charleston Area Medical Center, 3100 McCorkle Ave SE, Charleston, WV, 25302 and Charleston Area Medical Center Research Institute and Center for Clinical Sciences Research, 3200 McCorkle Ave SE, Charleston, WV, 25302

Correspondence:

Frank Annie M.A; MPA, PhD

Research Scientist

CAMC Health Education and Research Institute

3200 MacCorkle Ave. SE,

Charleston, WV 25304

Phone 304-388-9921

Fax: 304-388-9921

Email:Frank.H.Annie@camc.org

Total word count: 1317

Author Disclosure Block: None

Key words: NA

Running Title: NA 
Total Number of Tables and Figures: NA

\section{Background}

Originating in Wuhan, China at the end of 2019, Coronavirus 2019 (COVID-19) is a disease caused by severe acute respiratory syndrome coronavirus 2 (SARS-CoV-2) (1). The World Health Organization (WHO) first characterized COVID-19 as a pandemic on March 11, 2020 to promote the need for better detection and spread containment internationally (2). Healthcare facilities across the United States (U.S.) are significantly changing their operations to protect patients and employees from exposure, including use of telehealth communication for triage, assessment, and care for patients with mild illnesses (3). For emergency cases, the American College of Surgeons (ACS) recommend lead physicians and administrators organize alternative measures in response to trauma, cardiac, and stroke systems reaching full capacity when possible (4). While practice of social distancing is currently the best way to prevent overload of our healthcare system and protect our employees (5), the ACS, in compliance with CDC guidelines (6), gently reminds us that postponement of elective surgeries or procedures may eventually prompt emergent cases due to disease progression (7). When elective cases and procedures become emergent, non-deferrable interventions require strict adjustment of hospital protocol. Aside from minimization of contact and appropriate use of personal protective equipment (PPE) during mass casualty incident (MCI) response, major Italian surgical and anesthesiologic societies emphasize the need of segregation of COVID-19 and non-COVID-19 patients requiring surgery along with careful monitoring of resource usage such as staff, intensive care beds, material, and device conservation (8).

Singapore General Hospital, a large tertiary level acute care center, implemented some these disaster measures before Coccolini et al. published their insights. They divided surgical staff members, including on-call anesthesiologists, into two groups, in which one exclusively cared for patients infected or suspected to be infected with COVID-19 while the other group managed treatment for non-COVID-19 patients. They also postponed non-urgent preoperative assessment clinic visits, relocated elective surgeries for non-COVID-19 patients to their main operating room (OR) complex away from three smaller ORs housing COVID-19 cases, switched to stricter sanitary practices, and ran in situsimulations to prepare for unexpecting problems during crisis. With repetition, team members comprising various surgical disciplines improved their ability to address situational problems including scenarios involving infection control breaches and unsatisfactory equipment set-up (9). In accord with Singapore General Hospital, there are other organizations that aim to use their experiences with COVID-19 to create a system that best addresses the needs of all patients requiring procedural or surgical intervention. The Asian Pacific Society for Digestive Endoscopy affirms that deferment of elective procedures, such as non-emergent endoscopies, is essential to prevent further spread. However, they suggest that semi-urgent procedures be reviewed on a case by case basis (10). In collaboration with Asian and European Organizations, major departments of Otolaryngology across the U.S. are making strong efforts to emulate the strict safety guidelines employed by centers in Singapore and Hong Kong when considering intervention for patients who are not necessarily in need of emergent treatment (11).

Just prior to the COVID-19 pandemic declaration, evidence from China indicated case fatality rates in patients with preexisting comorbid conditions at $5.6 \%$ for cancer, $6.0 \%$ for hypertension, $6.3 \%$ for chronic respiratory disease, $7.3 \%$ for diabetes, and $10.5 \%$ for cardiovascular disease (CVD) (12). Though COVID19 is greatly associated with respiratory illness (13) in elderly patients (14), the impact of this virus on hypertension and cardiovascular disease (CVD) also requires significant attention given that SARS-CoV-2 infects host cells via angiotensin-converting enzyme 2 (ACE2) receptors. These receptors are highly expressed in both the lungs and heart (15). Considering the role of ACE2 in SARS-CoV-2 entry, there is much debate whether angiotensin-converting enzyme inhibitors (ACEIs) and angiotensin receptor blockers (ARBs) should be administered to hypertensive patients. However, there is currently little evidence that clearly shows whether ACEIs/ARBs inhibit ACE2 or upregulate it. Major organizations, including the American College of Cardiology (ACC) and the European Society of Cardiology, strongly recommend that physicians continue giving ACEIs/ARBs per standard protocol until further investigations suggest otherwise $(16,17)$. The ACC also cites the need for further investigation to determine the impact of COVID-19 on CVD-naïve patients that were otherwise healthy prior to infection (18). Though preoperative administration of ACEIs/ARBs 
remains the same, delaying surgery for non-COVID-19 and COVID-19 patients with chronic hypertension may negatively affect their care due to a highly individualized treatment regimen (19) that could be further complicated by disease progression.

In addition to the possible impact of COVID-19 on blood pressure management, its negative effects on patients with underlying CVD, potential cause of acute myocardial injury (20), and facilitation of the FDA's approval for use of extracorporeal membrane oxygenation (ECMO) in lieu of ventilators (21) pose great challenges for healthcare staff involved in cardiovascular care. The ACC and Society for Cardiovascular Angiography and Interventions (SCAI), in accord with other disciplines, recognizes that teams, including cardiac surgeons, interventional cardiologists, and anesthesiologists, must make difficult decisions regarding whether they should proceed with scheduled valvular or structural interventions. The ACC/SCAI advise teams move forward on a case by case basis (22). For example, it is currently reasonable to postpone scheduled transcatheter aortic valve replacement (TAVR) procedures for asymptomatic patients with severe aortic stenosis while monitoring them via telehealth communications as opposed to delaying intervention for symptomatic patients who are at high risk of clinical deterioration, prolonged hospital stay, or repeat hospitalization. Complexity becomes increasingly apparent, however, when considering symptomatic TAVR candidates who could also benefit from percutaneous coronary intervention (PCI). Per the ACC/SCAI consensus statement, PCI scheduled or recommended for symptomatic TAVR candidates before implantation of their new aortic valve should be deferred unless coronary artery disease (CAD) is affecting clinical presentation. Those on the front lines in Italy agree that comprehensive cardiovascular care need be multifaceted and integrative (23), suggesting that multidisciplinary organization and collaborative preparedness will help us better manage patients with CVD.

The COVID-19 Guidelines for Triage of Vascular Surgery Patients established by the ACS do provide some direction regarding non-emergent cases, such as allowing a surgeon to exercise judgment when considering repair of an abdominal aortic aneurysm $(\mathrm{AAA})>6.5 \mathrm{~cm}$ or revascularization for a high grade restenosis stemming from previous intervention (24). Though elective cases must be postponed, vascular department heads worldwide are collaborating on safe surgical and procedural measures for patients requiring nonemergent, as well as emergent, care. Vascular surgery leadership at Walter Reed National Military Medical Center conveys the importance of forming international partnerships, calling attention to how the U.S. military drew on the experiences of other nations and amassed their support to handle the crisis that took place on 9/11/2001 (25). The aforementioned safety measures that some health centers in Singapore are taking extend to their vascular surgery departments. Emulation of their team segregation practices, excellent use of telehealth, and resource conservation (26) will possibly better enable U.S. health systems to keep workers and patients safe while addressing gray areas related to elective surgery cancellations.

There is proposal of using some ambulatory surgery facilities, due to their closure, for resource contribution that may partially relieve the current strain on our healthcare system (27). Though additional evidence is needed to elucidate special safety measures and confirm the overall benefit of this suggestion, improved resource distribution may help U.S. organizations provide broader care without ignoring the situation at hand. Delaying interventions, especially for patients with vascular and/or structural heart disease, enables worsening of minor to moderate conditions. Additional evidence is necessary for determining how we can safely treat both non-COVID-19 and COVID-19 patients requiring surgeries or procedures during this pandemic, as cancellation of elective interventions may have larger implications than minor inconveniences. Literature citing association between past receipt or donation of organs and negative outcomes stemming from SARSCoV-2 are also lacking (28). Along with provision of multidisciplinary care for COVID-19 patients and the importance of adjusting to constantly evolving information, it is crucial for us to remember that there are non-infected persons with progressive diseases directly suffering from this crisis as well.

\section{References}

1. Gorbalenya, A. E. et al. Severe acute respiratory syndrome-related coronavirus - the species and its viruses, a statement of the Coronavirus Study Group. Preprint (2020) available from: https://www.biorxiv.org/content/10.1101/2020.02.07.937862v1 
2. WHO Director-General's opening remarks at the media briefing on COVID-19 - 11 March 2020. World Health Organization. [Internet]. 2020 [cited 2020 April 12]. Available from: https://www.who.int/dg/speeches/detail/who-director-general-s-opening-remarks-at-the-mediabriefing-on-covid-19-11-march-2020

3. Interim Guidance for Healthcare Facilities: Preparing for Community Transmission of COVID19 in the US. [Internet]. February 29, 2020. [Cited 2020 April 12]. Available from: https://www.cdc.gov/coronavirus/2019-ncov/hcp/guidance-hcf.html

4. Qualls N, Levitt A, Kanade N, et al. Community Mitigation Guidelines to Prevent Pandemic Influenza - United States, 2017. MMWR Recomm Rep 2017;66(No. RR-1):1-34. http://dx.doi.org/10.15585/mmwr.rr6601a1

5. American College of Surgeons. COVID-19: Guidance for Triage of Emergent Surgical Procedures. [Internet]. 2020 [cited 2020 April 12]. Available from: https://www.facs.org/covid-19/clinicalguidance/statement-maintaining

6. American College of Surgeons. COVID-19: Guidance for Triage of Non-Emergent Surgical Procedures. [Internet]. 2020 [cited 2020 April 12]. Available from: https://www.facs.org/covid-19/clinicalguidance/triage

7. American College of Surgeons. COVID-19: Recommendations for Management of Elective Surgical Procedures. [Internet]. 2020 [cited 2020 April 12]. Available from: https://www.facs.org/about-acs/covid19/information-for-surgeons/elective-surgery

8. Coccolini, F., Perrone, G., Chiarugi, M. et al. Surgery in COVID-19 patients: operational directives. World J Emerg Surg 15, 25 (2020). https://doi.org/10.1186/s13017-020-00307-2

9. Wong J, Goh QY, Tan Z, et al. Preparing for a COVID-19 pandemic: a review of operating room outbreak response measures in a large tertiary hospital in Singapore [published online ahead of print, 2020 Mar 11]. Se préparer pour la pandémie de COVID-19: revue des moyens déployés dans un bloc opératoire d'un grand hôpital tertiaire au Singapour [published online ahead of print, 2020 Mar 11]. Can J Anaesth . 2020;1-14. https://doi.org/10.1007/s12630-020-01620-9

10. Chiu PWY, Ng SC, Inoue H, et al. Practice of endoscopy during COVID-19 pandemic: position statements of the Asian Pacific Society for Digestive Endoscopy (APSDE-COVID statements). Gut . February 2020. https://doi.org/10.1136/gutjnl-2020-321185

11. Givi B, Schiff BA, Chinn SB, et al. Safety Recommendations for Evaluation and Surgery of the Head and Neck During the COVID-19 Pandemic. JAMA Otolaryngol Head Neck Surg. Published online March 31, 2020. https://doi.org/10.1001/jamaoto.2020.0780

12. $\mathrm{Wu} \mathrm{Z}$, McGoogan JM. Characteristics of and Important Lessons From the Coronavirus Disease 2019 (COVID-19) Outbreak in China: Summary of a Report of 72314 Cases From the Chinese Center for Disease Control and Prevention. JAMA. 2020;323(13):1239-1242. https://doi.org/10.1001/jama.2020.2648

13. C Huang, Y Wang, X Li, et al. Clinical features of patients infected with 2019 novel coronavirus in Wuhan, China. Lancet (2020) published online Jan 24. https://doi.org/10.1016/S0140-6736(20)301835

14. F Zhou, T Yu, R Du, G Fan, Y Liu, Z Liu, et al. Clinical course and risk factors for mortality of adult inpatients with COVID-19 in Wuhan, China: a retrospective cohort study. Lancet (2020 Mar 11), 10.1016/S0140-6736(20)30566-3 pii: S0140-6736(20)30566-3 [Epub ahead of print]

15. Turner AJ, Hiscox JA, Hooper NM. ACE2: from vasopeptidase to SARS virus receptor. Trends Pharmacol Sci . 2004;25(6):291-294. https://doi.org//10.1016/j.tips.2004.04.001

16. HFSA/ACC/AHA statement addresses concerns re: using RAAS antagonists in COVID-19. [Internet]. March 17, 2020. [cited 2020 April 13]. Available at: https://www.acc.org/latestin-cardiology/articles/2020/03/17/08/59/hfsa-acc-aha-statement-addresses-concerns-re-using-raasantagonists-in-covid-19

17. European Society of Cardiology. Position statement of the ESC Council on Hypertension on ACEinhibitors and angiotensin receptor blockers. [Internet]. March 13, 2020. [cited 2020 April 13]. Available from: https://www.escardio.org/Councils/Council-on-Hypertension-(CHT)/News/position- 
statement-of-the-esc-council-on-hypertension-on-ace-inhibitors-and-ang

18. Welt FGP, Shah PB, Aronow HD et al. Catheterization Laboratory Considerations During the Coronavirus (COVID 19) Pandemic: A Joint statement from the American College of Cardiology (ACC) Interventional Council and the Society of Cardiovascular Angiography and Intervention (SCAI). Journal of the American College of Cardiology. 2020 (submitted).

19. Ma TK, Kam KK, Yan BP, Lam YY. Renin-angiotensin-aldosterone system blockade for cardiovascular diseases: current status. Br J Pharmacol . 2010;160(6):1273-1292. https://doi.org//10.1111/j.1476$5381.2010 .00750 . x$

20. Zheng, Y., Ma, Y., Zhang, J. et al. COVID-19 and the cardiovascular system. Nat Rev Cardiol (2020). https://doi.org/10.1038/s41569-020-0360-5

21. https://www.fda.gov/media/136734/download

22. Shah P, Welt F, Mahmud E et al. Triage Considerations for Patients Referred for Structural Heart Disease Intervention During the Coronavirus Disease 2019 (COVID-19) Pandemic: An ACC/SCAI Consensus Statement. April 6, 2020. https://doi.org/10.1002/ccd.28910 [Preprint]

23. Biondi-Zoccai G, Landoni G, Carnevale R, Cavarretta E, Sciarretta S, Frati G. SARS-CoV-2 and COVID-19: facing the pandemic together as citizens and cardiovascular practitioners. Minerva Cardioangiol. 2020. https://doi.org/10.23736/S0026-4725.20.05250-0

24. COVID-19 Guidelines for Triage of Vascular Surgery Patients. American College of Surgeons. [Internet]. March 24, 2020. [cited 2020 April 11]. Retrieved from: https://www.facs.org/covid-19/clinicalguidance/elective-case/vascular-surgery

25. A military perspective on the vascular surgeon's response to the COVID-19 pandemic Rasmussen, Todd E. et al. Journal of Vascular Surgery. April 1, 2020. https://doi.org/10.1016/j.jvs.2020.03.036 (IN PRESS)

26. Ng JJ, Ho P, Dharmaraja RB, Wong JCL, Choong AMTL. The Global Impact of COVID-19 on Vascular Surgical Services. J Vasc Surg. 2020. https://doi.org/10.1016/j.jvs.2020.03.024 (IN PRESS)

27. Rajan, N, Joshi, G. The COVID-19 Role of Ambulatory Surgery Facilities in This Global Pandemic. International Anesthesia Research Society. E-pub ahead of print (April 1, 2020). Li F, Cai J, Dong N. First Cases of COVID-19 in Heart Transplantation From China, JHLT. 2020. (IN PRESS). 